\title{
THE PROBLEM OF THE ORDER OF THE CONJUNCTS IN THE COORDINATING CONJUNCTION 'AND': A LOGICAL-SYNTACTIC SOLUTION *
}

\author{
[ EL PROBLEMA DEL ORDEN DE LOS TÉRMINOS EN LA CONJUNCIÓN COPULATIVA 'Y': UNA \\ SOLUCIÓN LÓGICO-SINTÁCTICA ]
}

Miguel López-Astorga **

Talca University, Chile

\begin{abstract}
From the mental models theory, it has been claimed that the conjunction commutativity law, that is, the logical law providing that the order of the conjuncts joined by the coordinating conjunction 'and' can be changed without modifying the truth-value of the sentence, is not always valid in real conversations in natural language. For this reason, based on that very theory, it has been proposed that the true sense of a sentence of that kind can only be suitably captured by a semantic theory, such as the one of the mental models, which resorts to iconic possibilities describing reality. However, in this paper, it is argued that the formal and basically syntactic frameworks can also correctly stand for the actual meaning corresponding to propositions with a coordinating conjunction such as 'and' to which the conjunction commutativity law does not seem, in principle, to apply. To do that, they do not have to significantly move away from classical logic, but only to add to the connectives in this last logic a modal operator akin to 'Next' in temporal logic, and this without the need to assume many more temporal logical elements.
\end{abstract}

KEYWORDS: logic; mental models; semantics; syntax; temporal operator
Resumen: Desde la teoría de los modelos mentales, se ha defendido que la ley lógica de conmutatividad de la conjunción, esto es, la ley que establece que el orden de los términos unidos por la conjunción copulativa ' $y$ ' puede alterarse sin que se modifique por ello el valor de verdad de la sentencia, no necesariamente se cumple en conversaciones reales en lengua natural. Por ello, en base a dicha teoría, se ha propuesto que el verdadero sentido de una sentencia de tal índole solo puede ser captado adecuadamente por una teoría semántica, como la de los modelos mentales, que recurra a posibilidades icónicas descriptoras de la realidad. No obstante, en este trabajo se defiende que los marcos formales $y$ básicamente sintácticos también pueden representar correctamente el auténtico significado implicado por una proposición con la conjunción copulativa 'y' y para la que la ley de conmutatividad de la conjunción no parece, en un principio, válida. Para ello, no precisan distanciarse sustancialmente de la lógica clásica, sino únicamente incorporar a las conectivas de esta última lógica un operador modal semejante al operador Next en la lógica temporal, y ello sin necesidad de asumir muchos más elementos lógicos temporales.

Palabras-Clave: lógica; modelos mentales; semántica; sintaxis; operador temporal

\footnotetext{
* Acknowledgments:

This paper is a result of the Project CONICYT/FONDECYT/REGULAR/FOLIO $N^{\circ} 1180013$, "Recuperación de las formas lógicas de los enunciados a partir de un análisis de las posibilidades semánticas a las que hacen referencia”, supported by FONDECYT (National Fund for Scientific and Technological Development), Government of Chile. ** PhD. in Philosophy. Prof. at Institute of Humanistic Studies "Juan Ignacio Molina”, Talca University, Chile. m@ilto: milopez@utalca.cl
} 
The difference between [VI] and [VIII] is minimal, but it exists. In the second case, the fact that Viv fell over occurred before the fact that Pat pushed Viv. In this way, although it can be thought that the other facts in the universe remain in the same way in them, [VI] and [VIII] show that the mental 12 models theory has certain resources the syntactic theories lack. The first one can capture in a relatively easy way the nuances involved in the order of the conjuncts in a coordinating conjunction such as 'and', since it resorts to iconic models of reality. However, the second ones cannot, in principle, do so, as they use, basically, logical forms.

There is no doubt that current cognitive theories are somehow having an influence on the studies about language and the approaches related to the phenomenon of human communication. From this point of view, it can be interesting to note that, while most such theories nowadays give a clear and relevant role to pragmatics, not all of them value to the same extent the action of semantics and syntax (see, e.g., López-Astorga, 2016). Thus, for instance, the mental models theory (e.g., Khemlani, Byrne, \& Johnson-Laird, 2018; Khemlani, Hinterecker, \& Johnson-Laird, 2017; Oakhill \& Garnham, 1996) considers the human intellectual processes to be essentially semantic, and the mental logic theory (e.g., Braine \& O'Brien, 1998a; O'Brien, 2014) proposes, on the contrary, that syntax is what truly has an important function in the intellectual activity.

Obviously, these two theories have elements in common. Without the need to look for further evidence, as mentioned, at present, most frameworks acknowledge the importance of pragmatics, and neither of these theoretical proposals is an exception in this way. However, the differences between them are, as also pointed out, evident too, the problem being that the literature on cognitive science offers contradictory experimental data. In some cases, they support one of these theories and show the difficulties of the other one. Nevertheless, in other cases, they reverse the situation and the accepted and the questioned theories are the opposite (see, e.g., the works cited so far). Therefore, the task to search results, proofs, or even arguments that help one go for one of these frameworks appears to be critical.

Thus, there seem to be a fact detected by Orenes and Johnson-Laird (2012) that, in principle, can only be accounted for by the mental models theory, and hence appears to give primacy to this last approach. That fact refers to that the logical conjunction commutativity law (see, e.g., Deaño, 1999) does not seem to be fulfilled in all the cases in the daily talks carried out in natural language. The formal structure of that law can be expressed as follows:

$[\mathrm{I}]\left(\mathrm{X}^{\wedge} \mathrm{Y}\right) \leftrightarrow\left(\mathrm{Y}^{\wedge} \mathrm{X}\right)$ (Where '^’ is logical conjunction and ' $\leftrightarrow$ ' provides biconditional relationship).

And this formula, as it is well known, indicates that, when two conjuncts are joined by a logical conjunction, their order is not relevant. If the sentence is true when one of those conjuncts is the first or the left one, it is so when that very conjunct is the second or the right one as well.

Of course, the fact that there is no exact equivalences between words in natural language such as 'and' and logical connectives such as ' $\wedge$ ' is nothing new 
(in works such as, e.g., the one of Deaño, 1999, this is absolutely clear). Nonetheless, what Orenes and Johnson-Laird (2012) raise is that there are sentences with 'and' that, by virtue of the fact that [I] does not apply to them, can be expressed in no way using the language of classical propositional logic. So, this point can be considered to be a very important difficulty for formal or syntactic theories such as that of the mental logic, since those theories often work by resorting to formal schemata more or less (they do not always accept all the requirements of classical logic) similar to those of propositional calculus, seem to assume that individuals, when reasoning, translate the expressions in natural language into formulae akin to the ones of that calculus, and, in general, explicitly or implicitly, usually accept [I].

However, as indicated, the phenomenon is not a problem for the mental models theory. Because it works with possibilities representing reality in an iconic manner (e.g., Johnson-Laird, 2012), this last theory has a machinery that, at least prima facie, can avoid the difficulties caused by the circumstance commented on, and this is a fact so obvious that it will not challenged below. In this way, what this paper intends is just to show that the formal approaches can also face those difficulties by including in their general frameworks minimal assumptions coming from non-classical logics, and that hence the fact pointed out by Orenes and Johnson-Laird (2012) is not a critical element really proving that one of the approaches is the correct one either.

To achieve this, firstly, a more detailed description of the problem this paper addresses will be given, and the manner the mental models theory can solve it will be explained. From then on, secondly, the way an approach based on logical forms can propose a solution too will be accounted for. As argued below, the key is, simply, to add to its system an operator fulfilling a function akin to the one of Next in temporal logics.

The order of the conjuncts in the logical conjunction and the mental models theory

As it has been said and can be checked in works describing it, the mental models theory is an essentially semantic approach. Thus, it ignores logical forms and hence a clear syntax (see, e.g., Johnson-Laird, 2010). Following it, what is relevant in sentences is not their formal structure, but the relationships that can be provided between the concepts included in them from their meanings or their semantic content. In this way, based, as their proponents often explicitly indicate (see, e.g., Johnson-Laird, Khemlani, \& Goodwin, 2015), on arguments derived, in a more or less direct manner, from Peirce (1931-1958), it proposes that, when processing a sentence, individuals build iconic or symbolic models of it in which, if there is no additional change in the universe, that sentence can be true.

Accordingly, it is obvious that, under approaches such as this one, the problem raised by Orenes and Johnson-Laird (2012) regarding the order of the conjuncts in the coordinating conjunction 'and' disappears. And that can be noted just resorting to examples and arguments given by them. Following Orenes and Johnson-Laird (2012), there is no difficulty when the sentence is similar to this one:

[II] "Pat is tall and Viv is short" (Orenes \& Johnson-Laird, 2012, p. 357). 
Indeed, if $\mathrm{X}$ means 'Pat is tall' and $\mathrm{Y}$ denotes 'Viv is short', it can be said that, in this case, $[\mathrm{I}]$ is fulfilled, that is, that [II] has a semantic content equivalent to that of this sentence:

[III] "Viv is short and Pat is tall" (Orenes \& Johnson-Laird, 2012, p. 357).

Nevertheless, everything seems to change when what is expressed is something similar to:

[IV] "Pat pushed Viv and Viv fell over" (Orenes \& Johnson-Laird, 2012, p. 357).

Certainly, if the equivalences are now X: 'Pat pushed Viv' and Y: 'Viv fell over', it has to be acknowledged that, in this new example:

$$
[\mathrm{V}] \mathrm{X}^{\wedge} \mathrm{Y} \neq \mathrm{Y}^{\wedge} \mathrm{X}
$$

And the reason is evident. In [V], $\mathrm{X}^{\wedge} \mathrm{Y}$ indicates that Viv fell over because Pat pushed her, while $\mathrm{Y}^{\wedge} \mathrm{X}$ can refer to that, after Viv fell over, Pat pushed her, which reveals that the two sentences do not necessarily transmit the same information.

From the logical point of view, this is a problem at least for two reasons. On the one hand, the conjunction commutativity law, that is, [I], is a tautology, which means that, regardless of the truth-values of both $\mathrm{X}$ and $\mathrm{Y}$, it is always true with no exception. On the other hand, in classical propositional calculus, described, for instance, by Deaño (1999) and based on systems such as the one of Gentzen (1934, 1935), the derivation of $Y^{\wedge} X$ from the premise $X^{\wedge} Y$ and the deduction of $X^{\wedge} Y$ from the premise $\mathrm{Y}^{\wedge} \mathrm{X}$ are inferences very trivial and simple. So, the example provided by Orenes and Johnson-Laird (2012) is actually an important challenge for any theory being supported, to a greater or lesser extent, by fundamental elements of classical logic.

Undoubtedly, this is what happens with the mental logic theory. This last theory does not claim that the human being reasons by rigorously using the rules included in classical propositional calculus at all. Nonetheless, it only rejects the rules and assumptions of that calculus that, following the results obtained in empirical researches, do not appear to have a real influence on the human mind, the most relevant point for this paper being that it does seem to admit the rules of classical calculus that allow deriving both $\mathrm{Y}^{\wedge} \mathrm{X}$ from $\mathrm{X}^{\wedge} \mathrm{Y}$ and $\mathrm{X}^{\wedge} \mathrm{Y}$ from $\mathrm{Y}^{\wedge} \mathrm{X}$, and hence [I] (see, e.g. Braine \& O’Brien, 1998b).

However, as said, the problem does not exist under the framework of the mental models theory. As it can be derived from the explanation given by Orenes and Johnson-Laird (2012), under it, sentences such as [IV] cannot be expressed by means of logical forms such as $\mathrm{X}^{\wedge} \mathrm{Y}$. Such sentences refer, as also mentioned, to iconic models of reality, the suitable one for [IV] being akin to this one: 
[VI] (Pat pushed Viv) \&, after that, (Viv fell over)

It can be interpreted that, according the literature on the mental models theory, [VI] does not only describe the situation of Pat and Viv, but it also represents a circumstance of the entire universe in which, any other facts remaining in the same way, Pat has pushed Viv, and, as a consequence, Viv has fallen over. This, nonetheless, is not necessarily the model corresponding to:

[VII] "Viv fell over and Pat pushed her" (Orenes \& Johnson-Laird, 2012, p. 357).

Keeping paying attention to Orenes and Johnson-Laird's account, it can be said that, for [VII], the model could be expressed in a manner such as the following:

[VIII] (Viv fell over) \&, after that, (Pat pushed her)

The difference between [VI] and [VIII] is minimal, but it exists. In the second case, the fact that Viv fell over occurred before the fact that Pat pushed Viv. In this way, although it can be thought that the other facts in the universe remain in the same way in them, [VI] and [VIII] show that the mental models theory has certain resources the syntactic theories lack. The first one can capture in a relatively easy way the nuances involved in the order of the conjuncts in a coordinating conjunction such as 'and', since it resorts to iconic models of reality. However, the second ones cannot, in principle, do so, as they use, basically, logical forms.

Nevertheless, this situation can be reversed with reasonable effort. Without assuming extremely radical assumptions, the syntactic theories can enhance their scope and also have the potential to capture the differences in content that can be caused when the order of the conjuncts in a logical conjunction is changed. This is exactly what the next section tries to show. instants

The formal theories, the coordinating conjunction 'and', and temporal

There is no doubt, and the Orenes and Johnson-Laird's (2012) comments on arguments such as, for example, those of Grice (1989) can be interesting in this regard, that there are pragmatic situations in which [VII] may not refer to [VIII] but to [VI], or, in other words, in which there would not be difference between assigning to that sentence a logical form such as $\mathrm{X}^{\wedge} \mathrm{Y}$ and a logical form such as $\mathrm{Y}$ $\wedge \mathrm{X}$. Think, for example, about the hypothetical case in which somebody asked what happened to Viv and why. If the answer to the question were, precisely, [VII], it is evident that what this last sentence would transmit would be much better expressed by [VI] than by [VIII], since it is clear that it would imply that the first fact that occurred was the fact that Pat pushed Viv.

But, beyond this possibility and assuming that [IV] and [VII] have different meanings, it can be stated that the difference between these two sentences could also be expressed, as pointed out, by a basically syntactic or formal theory that only added minimal elements provided by temporal logics to its assumptions. Thus, a 
relevant point of the account that will be presented below is that, as it can be inferred from all what has been said above, it can be valid not only for the mental logic theory, but also for any formal approach in which [I] is an accepted law, including, of course, the one classical logic can give and, therefore, works such as those of Gentzen $(1934,1935)$.

It is true that nowadays it is very hard to argue in favor of the idea that human beings reason by virtue of the principles of classical logic. That is shown by many studies in the literature on contemporary cognitive science. Thus, just taking one of the papers cited above into account, it can be said that in Orenes and Johnson-Laird (2012), in addition to the problem with regard to the logical conjunction indicates, other difficulties related to the conditional and disjunction in propositional calculus are analyzed. In this way, it can be stated that perhaps what is usual at present is not to support that the human mind is regulated by classical logic, but to propose theories such as the one of the mental logic, which, as mentioned, does not exactly coincide with all what is provided by classical logic (see also, in addition to the works supporting the mental logic theory, e.g., LópezAstorga, 2015, 2016). Nonetheless, given that the main goal of this paper is not to address discussions such as that one, it can reiterated that, regardless of the theoretical position one might have in connection to this last point, the arguments below can apply to any syntactic theory in which conjunction works in a way consistent with [I], which is something that, as indicated, happens in theories such as that of the mental logic, but not only in them.

Basically, the idea that will be supported here is that, with a minimal assumption such as the one made in papers such as, for example, that of LópezAstorga (2014), the problem of the conjunction 'and' in the framework of the formal theories is solved. López-Astorga's (2014) paper deals with a disputed task, Peter Wason's four cards selection task (e.g., Wason, 1966, 1968), which is also precisely one of the tasks that have been used to try to demonstrate that the relationship between the human mind and classical logic is not as evident as, in principle, one might suppose. However, what is interesting here is that that paper offers certain arguments to explain what happens when a group of participants attempts to execute the mentioned task that, in the same way, can be used to give the formal approaches the resources needed to be able to consider the differences of sense that a change in the order of the conjuncts of a particular conjunction can cause. Such arguments essentially consist of, ignoring neither that it is not really possible to speak about a temporal logic, but a plurality of temporal logics, nor that such systems often include several non-classical operators, taking from them only two elements to add them to the general syntactic framework assumed. Such elements are the semantics (in the specific sense that this word has in logic, and not necessarily in linguistics or cognitive science) of instants or moments in time and an operator akin to the one that in those logics is usually called Next and is represented by the symbol ' $\mathrm{N}$ ' (López-Astorga, 2014, pp. 62-63).

As far as the logical semantics is concerned, the idea is to include, as it is done in papers such as the one of López-Astorga (2014), a set $\left\{\mathrm{t}_{1}, \mathrm{t}_{2} \ldots \mathrm{tn}\right\}$ that can be denominated $\mathrm{T}$, which refers to moments in time and, in general, has all the characteristics attributed to it in works such as the one of Vázquez (2001). The function of $\mathrm{T}$ in the general system, which is also explained in detail in works such 
as the one of López-Astorga (2014), who attributes to it the mentioned characteristics as well, is obvious. The propositions can change their truth-values in different instants in time. Thus, for example, it is absolutely possible that $\mathrm{X}\left(\mathrm{t}_{1}\right)$, that is, $\mathrm{X}$ in temporal moment 1 , is true, and that $\mathrm{X}\left(\mathrm{t}_{2}\right)$, that is, $\mathrm{X}$ in temporal instant 2 , is false.

On the other hand, the role of an operator such as $\mathrm{N}$ is necessary, again, as in works such as that of López-Astorga (2014), to refer to the truth-value of a proposition in the moment following, with no intermediate moment, the moment in which the proposition would be if that operator were not present. In other words, if $X$ has a truth-value in, for example, $t_{1}, N X$ refers to the truth-value of $X$ in $t_{2}$. Nonetheless, since no entire temporal logic is being assumed in this paper, and, for that reason, this operator does not have here exactly the same functions and properties temporal logics often assign to it, maybe, in a manner different from the one followed in López-Astorga (2014), it can be more suitable to represent it below with a symbol different from the usual one. In this way, taking the meaning of Next into account, and with the sole objective of reflecting that the operator that is being used in this paper, while it is similar to N, it is not exactly the same as it, an option can be to resort to the letter ' $\mathrm{D}$ ', which is the initial of the Latin word Deinde, whose meaning is, as known, akin to the one of Next in English.

Thus, this allows expressing, by means of a simple logical formula, the real structure of a sentence such as [IV] without ignoring the temporal dimension present in it. Keeping the same equivalences above, the formula would be as follows:

\section{$[\mathrm{IX}] \mathrm{X}^{\wedge} \mathrm{DY}$}

Which (assuming that $t_{1} \leq t_{i} \leq t_{n}$ ) indicates that $X$ is true in $t_{i}$ (i.e., that Pat pushed Viv in instant $\mathrm{i}$ ), and that $\mathrm{Y}$ is true in $\mathrm{t}_{\mathrm{i}+1}$ (i.e., that Viv fell over in instant $\mathrm{i}+1)$.

Likewise, these assumptions also enable to avoid the problems linked to the conjunction commutativity law regarding conjunctions such as [IV] reported by Orenes and Johnson-Laird (2012). And this is so because, now, it is possible to change the order of the conjuncts without modifying the sense of the sentence. Indeed, because of an operator such as D, a formula such as the following:

$$
[\mathrm{X}] \mathrm{DY} \wedge \mathrm{X}
$$

Means exactly the same as [IX]. D clarifies the temporal order of the facts, no matter which the order of the conjuncts in the formula is. Both in [IX] and in $[\mathrm{X}]$, firstly, Pat pushes and then, in a second moment, Viv falls over. So, from a syntactic or formal perspective, what is important to avoid the difficulties is to note that the actual logical form of a sentence such as [IV] is not a formula such as $\mathrm{X}^{\wedge}$ $\mathrm{Y}$, but such as [IX] (or $[\mathrm{X}]$ ), and, in this way, [I] continues to be valid in the framework and is no longer a problem.

Accordingly, it cannot be said that the formal theories essentially based on syntax are not able to stand for the circumstances in which a conjunct in a logical 
conjunction happens before the other one. It is true that additional assumptions are necessary, but such assumptions are neither many nor complex. In the same way, they do not have to necessarily impair in a significant manner the general lines of the logical framework accepted and used. And all of this, ultimately, means that the problem pointed out by Orenes and Johnson-Laird (2012) is not a real problem for the syntactic approaches.

\section{Conclusions}

Therefore, this paper is one more proof that the debate between semantic frameworks such as the one of the mental models theory and syntactic approaches such as the one of the mental logic theory is not finished yet (see, e.g., LópezAstorga, 2015). Clear evidence is still needed to make a decision on the discussion about which of these two perspectives is more appropriate, since the fact raised by Orenes and Johnson-Laird (2012) analyzed here does not seem to be an undisputable proof in this regard. As seen, that is a problem that, while the semantic theories can solve very easily, the syntactic theories can face with some more assumptions that do not modify their general proposal in a relevant way. Hence, it appears that the task to search indications that allow one to come closer to the end of the discussion should continue.

However, as claimed in, for example, López-Astorga (2015), perhaps there is a third possibility: both approaches can be correct at the same time and describe different aspects of the intellectual and linguistic activity that are actually complementary. Certainly, pragmatics, semantics, and syntax are three aspects involved in language, and none of them can be ignored. For this reason, it is justified to think that these three dimensions should also be present, in the same way, in any proposal trying to describe how the human intellectual activity works in general. Pragmatics is not, in principle, a problem, since, as it has been indicated and can be checked in the specialized literature, it is not just accepted both by the mental models theory and by the mental logic theory, but it is a very important element in both of them (as indicated, see, in addition to works supporting these two theoretical frameworks, e.g., López-Astorga, 2016). Nevertheless, likewise, it could be thought that, as said, in the same manner as it happens in language, semantics and syntax cannot be deemed as two separated elements in cognition either.

From this point of view, it seems to be absolutely appropriate to question about why the point of departure is often that the two approaches addressed here are necessarily contradictory. Truly, iconic models such as those of the mental models theory can have a syntactic correspondence linked to formulae or schemata such as those of the mental logic theory, and the formulae or schemata of this last theory can have a semantic correspondence linked to the iconic models of the mental models theory too. In fact, the separation between semantics and syntax does not make sense in classical logic, and papers such as the one of López-Astorga (2015) propose explicit preliminary elements for a possible cognitive framework joining the semantic and syntactic perspectives.

In any case, it can be said that even some proponents of the mental logic theory admit the possibility that its inference schemata can be compatible with 
semantic mental models of any kind (e.g., O'Brien, 1998), and that, for all of this, it seems to be suitable to propose, as it is done in works such as, for example, some of those cited above, that this is the direction to follow in the future research on these issues. The difficulty to find facts or clear results that lead one to accept one of the perspectives reviewed and to reject the other one appears to be already a proof that maybe it is not worth keeping looking for facts or results of that type. Perhaps they are not found because they do not exist and, therefore, the time to become aware of that is coming.

\section{REFERENCES}

BRAINE, M. D. S.; O’BRIEN, D. P. (eds.). Mental Logic. Mahwah, NJ: Lawrence Erlbaum Associates, Inc., Publishers, 1998a.

BRAINE, M. D. S.; O'BRIEN, D. P. The theory of mental-propositional logic: Description and illustration. In: BRAINE, M. D. S; O'BRIEN, D. P. eds. Mental Logic. Mahwah, NJ: Lawrence Erlbaum Associates, Inc., Publishers, pp. 79-89, 1998 b.

DEAÑO, A. Introducción a la lógica formal. Madrid, Spain: Alianza Editorial, 1999.

GENTZEN, G. "Untersuchungen über das logische Schließen I." Mathematische Zeitschrift, 39(2): pp. 176-210, 1934.

GENTZEN, G. "Untersuchungen über das logische Schließen II." Mathematische Zeitschrift, 39(3): pp. 405-431, 1935.

GRICE, H. P. Studies in the Way of Words. Cambridge, MA: Harvard University Press, 1989.

JOHNSON-LAIRD, P. N. "Against logical form." Psychologica Belgica, 50(3/4): pp. 193-221, 2010.

JOHNSON-LAIRD, P. N. Inference with mental models. In: HOLYOAK, K. J.; MORRISON, R. G. eds. The Oxford Handbook of Thinking and Reasoning. New York, NY: Oxford University Press, pp. 134-145, 2012.

JOHNSON-LAIRD, P. N.; KHEMLANI, S.; GOODWIN, G. P. "Logic, probability, and human reasoning." Trends in Cognitive Sciences, 19(4): pp. 201-214, 2015.

KHEMLANI, S.; BYRNE, R. M. J.; JOHNSON-LAIRD, P. N. "Facts and possibilities: A modelbased theory of sentential reasoning." Cognitive Science, 42(6): pp. 1887-1924, 2018.

KHEMLANI, S.; HINTERECKER, T.; JOHNSON-LAIRD, P. N. "The provenance of modal inference.” In: GUNZELMANN, G.; HOWES, A.; TENBRINK, T.; DAVELAAR, E. J. eds. Proceedings of the $39^{\text {th }}$ Annual Conference of the Cognitive Science Society. Austin, TX: Cognitive Science Society, pp. 259-264, 2017.

LÓPEZ-ASTORGA, M. "Análisis de la tarea de selección por medio de una semántica temporal." Praxis Filosófica, 38: pp. 53-70, 2014.

LÓPEZ-ASTORGA, M. "The disjunction introduction rule: Syntactic and semantic considerations." Pragmalingüistica, 23: pp. 141-149, 2015.

LÓPEZ-ASTORGA, M. "Logic, pragmatics, and types of conditionals." Frontiers of Philosophy in China, 11(2): pp. 279-297, 2016.

OAKHILL, J.; GARNHAM, A. (eds.). Mental Models in Cognitive Science. Essays in Honour of Phil Johnson-Laird. Hove, UK: Psychology Press, 1996.

O'BRIEN, D. P. Mental logic and irrationality: We can put a man on the moon so why can't we solve those logical reasoning problems? In: BRAINE, M. D. S.; O'BRIEN, D. P. eds. Mental Logic. Mahwah, NJ: Lawrence Erlbaum Associates, Inc., Publishers, pp. 23-43, 1998.

O'BRIEN, D. P. "Conditionals and disjunctions in mental-logic theory: A response to Liu and Chou (2012) and to López-Astorga (2013)." Universum, 29(2): pp. 221-235, 2014.

ORENES, I.; JOHNSON-LAIRD, P. N. "Logic, models, and paradoxical inferences." Mind \& Language, 27(4): pp. 357-377, 2012.

PEIRCE, C. S. Collected papers of Charles Sanders Peirce. HARTSHORNE, C.; WEISS, P.; 
BURKS, A. eds. Cambridge, MA: Harvard University Press, 1931-1958.

VÁZQUEZ, M. "Breve introducción a la lógica temporal.” Revista Laguna, 9: pp. 187-198, 2001. WASON, P. C. Reasoning. In: FOSS, B. comp. New Horizons in Psychology. Harmondsworth (Middlesex), UK: Penguin, pp. 135-151, 1966.

WASON, P. C. "Reasoning about a rule." Quarterly Journal of Experimental Psychology, 20: pp. 273-281, 1968. 